\title{
Analysis of Temperature Changes on Electricity Consumption in Fars Province
}

\author{
Ali Akbar Salehizade \\ M.A. Islamic Azad University, Najafabad Branch, Najafabad, Iran \\ Mohammad Rahmanian \\ M.A. Islamic Azad University, Larestan Branch, Larestan, Iran \\ Manuchehr Farajzadeh
}

ASL.Ph.D. Tarbiat Modares University, Tehran, Iran

\begin{abstract}
Abdolhossein Ayoubi*
M.Sc. Student of Medical Informatics Technology, Biomedical Engineering Department, Amirkabir University of Technology, Tehran Iran, Address: 7th Andisheh St, Moallem Ave, Jahrom, Fars, Iran, Postal Code: 7417766486, Iran, P.O.Box: 445, Jahrom, Iran Email Address: ayoubi.hossein@gmail.com
\end{abstract}

\section{Doi:10.5901/mjss.2015.v6n3s2p610}

\section{Abstract}

Climate change is one of the factors that effects on electricity consumption behavior and changes in load of the network. Meanwhile, temperature is the most important factor because the use of heating and cooling devices in large scale. In this paper, the effects of air temperature fluctuations on electricity consumption with the help of temperature coefficient and Weighted-population index are brought into consideration. Then, the network load dependency from air temperature changing is analyzed. After that, through applying HDD and CDD indexes load sensitivity to air temperature in cooling and heating period of the year is calculated. Analyses of elasticity coefficient of load and air temperature are the last step in monitoring the fluctuations in electricity consumption in hot and cold weather. Also, comparing seasonal temperature variations with load table and temperature correlation coefficients show very close relationship between these two. Correlation coefficient is approximately 0.90 in several months of the year.

Keywords: Air Temperature Changes, Fars Load Network Changes, Weighted-population Index, Elasticity Coefficient

\section{Introduction}

Due to geographical location, climate variability, long hot season beside heavy industries and agricultural boom, Fars province has become one of the largest consumers of electricity. The important factors affecting power consumption are the main concern for the planners of the electricity industry in the province. Analyzing consumption pattern, the effect of air temperature and environmental conditions also industrial development and population growth in electricity consumption can be considered as good techniques for programmers to control the growth of power consumption and to find proper strategy for the optimal use of electricity (power management). Air temperature variations increase heating and cooling devises operation, so they have deep effects on Fars network load. In order to analyze the behavior of the network, simultaneous electricity load information was used during 2003-2012. Moderate growth of annual energy consumption and the peak of electricity load in Fars network during the mentioned years are 7.6 and 9.3 percent, respectively (Dispatching Center of Fars Regional Electric Company, 2012).

Electricity load in Fars network is being affected by high seasonal changes because of specific climate condition in the region. Thus, load peak in summer is almost 2 times higher than winter, so the result is variation in network load during these two periods. Therefore, we can divide Fars in two different parts to show weather fluctuations, warm period (April to October) and cold and moderate period (November to March). Cooling load is the most effective factor in using electricity and load peak in network with the use of cooling devises in warm period in most cities (Cooling load is created by using cooling devises in hot weather.). By regard to suitable environmental condition of the region, lighting load is 
floating on the network as the most effective factor in cool period of the year. In this paper, the effects of temperature changes on electricity consumption and load variations are studied. To reach this aim, network load variation index and province temperature coefficient are calculated. One of the most important studies in the world is 'Impacts of Climate Change on Electricity Consumption' done by Aroonruengsawat and Auffhammer (2009). This study simulates the impacts of higher temperatures resulted from anthropogenic climate change on residential electricity consumption in California. Flexible temperature response functions are estimated by climate zone which allows for differential effects of days in different temperature bins on households' electricity consumption. The estimation uses a comprehensive household level data set of billing data for California's three investor-owned utilities. Ehterami (2009) did the same study about the effects of air temperature change in electricity consumption in Khoozestan'. 'Formal Modeling and Assessment of Change over Time Power Consumption Simulation Based on Multi-variable Regression' by Ahmadi and Asadzadeh is another study. Regression model used in this paper is a system of 24 multi- variable equations which is solved by seemingly unrelated regressions. Three different scenarios of changing times were analyzed: the changing times, changing times expansion, double time change. Seemingly unrelated regression models with data gathered from 2005 to 2007 show that according to changing-time variable, the consumption reduction potential is estimated as 162.9 megawatt hours (equivalent to 0.87 percent of total consumption in 2007 spring and summer) and peak reduction potential in this scenario is estimated as $102 \mathrm{MW}$ which is equivalent to $1.9 \%$ reduction in peak hour.

\section{Materials and Methods}

\subsection{General Characteristics of Fars Province}

Fars is one of the 31 provinces of Iran. It is located in Southern part of the country. The province with an area of about 122,608 square kilometers is the fifth largest with a population of 4,528,513 people, (according to the National Statistics in 2011), also the fourth most populous province in Iran. According to statistics, Shiraz with its suburbs which has a population of 1,749,926 people is the most populous city in the province. Other populous cities of the province are namely Marvdasht, Kazeroon, Jahrom, and Fasa.

Fars Province is located in the South-central region on North latitude between the orbit of 27 degrees and 2 minutes and the orbit of 31 degrees and 42 minutes also on the East of the Greenwich meridian between 50 degrees and 42 minutes and 55 degrees and 38 minutes. It's adjacent to Isfahan province and Yazd province from the North, Bakhtyari province and Bushehr province from the West, Hormozgan province from the South and to Kerman province from the East.

According to the latest divisions, in May 2012, Fars with Shiraz as its capital includes 29 cities, 94 towns, 204 villages. Cities in Fars are as follows: Abadeh, Arsanjan, Estahban, Eghlid, Bavanat, Pasargad, Jahrom, Khoram Bid, Khonj, Zarrin Dasht, Darab., Sepidan, Shiraz, Frashbnd, Fasa, Firouzabad, Qyrvkarzyn Kazeroun, Lar, Lamerd, marvdasht mamasani, Neyriz. Figure 1 Shows Fars location in Iran.

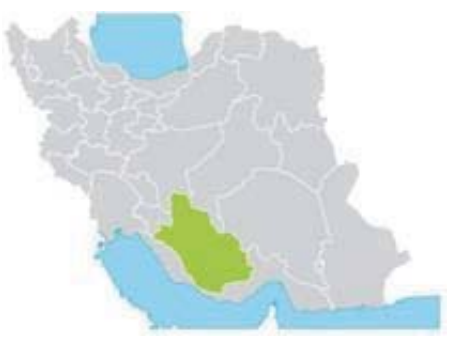

Fig 1. Fars Location in Iran

Generally in Iran and particularly in Fars province, air Temperature is a function of height, latitude and the amount of moisture in atmosphere. Effect of height in temperature is more visible than the effect of latitude. According to the thermal regime of Fars, January with the average temperature around $8.2^{\circ} \mathrm{C}$ and July with $31.7^{\circ} \mathrm{C}$ are the coldest and the warmest months of the year. Fars average annual temperature is $17.8^{\circ} \mathrm{C}$, and the pattern indicates that the weather gets warmer from West to East and from North to South. The chain of mountains in the west is the cause of the

${ }^{1}$ Khoozestan is one of South-West provinces in Iran. 
temperature rise from West to East; in addition the increase in temperature from north to south is due to the sun angle.

There are three different climates in the province; mild winter and cool summer which are seen in the mountainous region in North and North West, rainy and cold winter with rough, hot and dry summer which are considered as the signs of central regions, indeed few rainfalls in winter, spring and summer with moderate winters and very hot summers which are distinguished in South and South-east which is due to the low altitude of the mountains.

\section{Data Used}

The data used in this paper are weather information (air temperature) and simultaneous electricity load in Fars province; the probable connection between these two factors is studied after the classifications which were done through accurate calculation methods.

\section{Methods}

The main approach of this research is comparison among temperature fluctuations and changes in power consumption. Now, in order to get familiar with the article procedure, all calculus methods will be explained briefly.

\subsection{Correlation between Energy and Temperature}

After calculating the correlation coefficient between energy consumption and air temperature, their relationship will be studied.

Then, temperature coefficient of the region is calculated with the use of weight - population coefficient of the province, and finally the article has been completed with the calculation of HDD and CDD indices. So, this is the function of temperature index (TI) and weight - population coefficient of Fars province (Caselles.V, 2001),( Giannakopoulos , Psiloglou.E, 2006) :

1. $T I_{t}=\sum_{i=1}^{7} T_{t i} W_{i}$

$T I_{t}=$ Temperature Coefficient on Day ' $\mathrm{t}$ '

$T_{t i}=$ Maximum Temperature of Day 't' in 'i' Meteorological Station

$W_{i}=$ Weight - population Factor of the Province Meteorological Stations; it is calculated as follows: 2. $W_{i}=\frac{p_{i}}{\sum_{i=1}^{7} p_{i}}$

$p_{i}=$ City Population 'i' which Is under Study to Calculate Temperature Index (TI)

\section{HDD, CDD Indices}

To calculate the heating and cooling load in the network with the use of temperature index (TI), first of all, we should calculate the heating degree day (HDD) and the cooling degree day (CDD) as follows: [D. Gyalistras et al., 2006].

3. $C D D=\max \left(T I-T I^{*}\right)$

4. $H D D=\max \left(T I^{* *}-T I\right)$

$T I^{*}$ and $T I^{* *}$ is the basis of heating and cooling air temperature, respectively, which can be equal or they can be different from each other based on the level of thermal comfort system.

\section{Elasticity Coefficient}

Elasticity coefficient here shows the sensitivity of network's load to air temperature variations. That means whether power consumption faces more fluctuation in hot or cold weather.

In order to evaluate the relationship between elasticity coefficients, changes in network load and heating and cooling systems can be describe as follows : (Caselles.V, 2001).
5. $\varepsilon_{C D D}=\frac{C D D}{L_{C D D}} f^{\prime}(C D D)$
6. $\varepsilon_{H D D}=\frac{H D D}{L_{H D D}} g^{\prime}(H D D)$

Previous studies have shown that among all indicators of environmental conditions, including humidity, wind speed, air temperature, barometric pressure, etc., the air temperature can affect more in power consumption.

In order to calculate the temperature coefficient (TI) based on the location of weather stations, First, weight - 
population coefficient is calculated as shown in table 1. And then, the sample amounts of $\mathrm{TI}$ for each station on July $1^{\text {st }}$ and January $1^{\text {st }}$ are calculated as shown in table 2.

Table 1. Weight-population Coefficient

\begin{tabular}{|c|c|c|c|}
\hline Weather Station & City & Weight Index $\left(\mathcal{W}_{\mathrm{i}}\right)$ & Population \\
\hline Egghlid & Eghlid & 0.04 & 111377 \\
\hline Jahrom & Jahrom & 0.077 & 211391 \\
\hline Shiraz & Shiraz & 0.64 & 1749926 \\
\hline Firuzabad & Firuzabad & 0.044 & 121775 \\
\hline Kazeroon & Kazeroon & 0.101 & 278343 \\
\hline Lar & Lar & 0.054 & 149097 \\
\hline Niriz & Niriz & 0.41 & 112152 \\
\hline \multicolumn{2}{|r}{} \\
\hline
\end{tabular}

Table 2. Sample Amount of $\mathrm{TI}$ on July $1^{\text {st }}$ and January $1^{\text {st }}$

\begin{tabular}{|c|c|c|c|c|c|}
\hline City & Aug. 1st $2009 T_{t i}$ & Jan. 1 ${ }^{\text {st }} 2009 T_{t i}$ & $W_{i}$ & Aug. 1st $2009 T_{t}$ & Jan. 1st $2009 T_{t}$ \\
\hline Eghlid & 28.8 & 7.5 & 0.04 & 1.152 & 0.3 \\
\hline Shiraz & 36.5 & 14.3 & 0.64 & 23.36 & 9.15 \\
\hline Jahrom & 39.7 & 17.7 & 0.077 & 3.05 & 1.36 \\
\hline Firoozabad & 29.1 & 8.8 & 0.044 & 1.28 & 0.38 \\
\hline Kazeroon & 35.3 & 15.3 & 0.101 & 3.56 & 1.54 \\
\hline Lar & 41.9 & 20 & 0.054 & 2.26 & 1.08 \\
\hline Niriz & 35.1 & 16.4 & 0.041 & 1.43 & 0.67 \\
\hline$T I_{t}=\sum_{i=1}^{7} T_{t i} W_{i}$ & & & & 36.09 & 14.48 \\
\hline
\end{tabular}

\section{Results and Discussion}

\subsection{Analysis of the Correlation between Temperature and Power Consumption}

The temperature rise can be seen in April and May. In early April the temperature is between $26-13^{\circ} \mathrm{C}$, and the mean temperature is equal to $19.5^{\circ} \mathrm{C}$. Moderate weather temperate and New Year holidays are two main factors that prevent considerable changes in network load variations. Correlation coefficient during this period (April and May) is 0.92 . The average air temperature increases from $19^{\circ} \mathrm{C}$ to $25^{\circ} \mathrm{C}$ since the middle of April and in May; meanwhile the network load is dependent on the air temperature. It should be noted that for each 6 degrees of increase in the amount of $\mathrm{TI}$, the average network load increases around $207 \mathrm{MW}$ during the years studied. Thus, change on the air temperature level from (13-27) to (17-30) is the reason of load dependence to environment temperature and causes a vivid increase on network load. Correlation coefficient between load and temperature is 0.88 during this period.

Table 3. Correlation Coefficients in a Year

\begin{tabular}{|c|c|c|c|c|c|c|c|c|c|c|c|c|}
\hline & January & February & March & April & May & June & July & August & September & October & November & December \\
\hline Eghlid & $11-$. & $13-$. & 12. & 84.0 & 0.86 & 8. & 85. & 9. & 84. & 81. & 8. & $4-$. \\
\hline Shiraz & $1-$. & $11-$. & 1. & 0.9 & 0.89 & 71. & 91. & 94. & 91. & 78. & 7. & $28-$. \\
\hline Jahrom & $09-$. & $11-$. & 1. & 0.92 & 0.91 & 0.7 & 93. & 94. & 9. & 76. & .72 & $27-$. \\
\hline Firooz abad & -.1 & $1-$. & 09. & 0.85 & 84. & 79. & 9. & 91. & .86 & 7. & 78. & $33-$. \\
\hline Kazeroon & $08-$. & -.1 & 07. & 0.91 & 92. & 71. & 9. & 95. & 92. & 77. & 73. & $29-$. \\
\hline Lar & $08-$. & $09-$. & 08. & 0.97 & 96. & 69. & 95. & 98. & 97. & 89. & 7. & $.27-$ \\
\hline Niriz & $1-$. & $12-$. & 11. & 0.93 & 91. & 75. & 92. & 92. & 92. & 79. & 76. & $26-$. \\
\hline
\end{tabular}

The dependence between load and temperature is undoubtedly because of making use of air conditioners in hot air. During June, the average temperature will increase. And the increase in the temperature causes an increase in the average network load level up to $1081 \mathrm{MW}$; that is mostly cooling load. So, the change in temperature from 19 degree to 25 degree make the network load to be higher than previous levels while this over load is very remarkable. 
Correlation coefficient of load and temperature is 0.72 during June. The average temperature has increased during July and August, but there hasn't been a significant increase in the network load. The reason is that almost all of cooling devices are used before this period, and the increase in air temperature up to this level results in the rise in the electric power of the devices. Correlation coefficient is 0.9 and 0.94 during July and August, respectively. The heating period is over during September and October, and the average temperature is reduced. Correlation coefficient is 0.92 and 0.77 during September and October. It should be mentioned that cold period of the year starts from early November. Changes in the temperature level from $29^{\circ} \mathrm{C}$ to $15^{\circ} \mathrm{C}$ starts moderate weather conditions all over the province so that the over load which was caused by using electric cooling systems is reduced. Again, mild weather conditions reduce $390 \mathrm{MW}$ of network load amount. Correlation coefficient is 0.72 during November. With the start of the cold period, during December, January and February, the network load starts to increase by the use of electric heating equipments. But this jump is not comparable with the increase which appears in the hot period. Making use of gas energy instead of electric power for making heat in houses seems to be the reason.

Statistics show an inversion on correlation between the load and air temperature during this period; so, the correlation in December, January and February are $-0.29,-0.09$ and -0.1 , respectively. The load is less affected by temperature due to the moderate conditions in November and December; so correlation coefficient is reduced.

\section{CDD and HDD Analysis}

The base temperature for calculating $\mathrm{HDD}$ is $15^{\circ} \mathrm{C}$, and it is $21^{\circ} \mathrm{C}$ for $\mathrm{CDD}$ calculations (Caselles, 2001). But, the base temperatures of $\mathrm{HDD}$ and $\mathrm{CDD}$ in Fars province are $17^{\circ} \mathrm{C}$ and $27^{\circ} \mathrm{C}$, respectively. The following maps show heating and cooling zoning in each season. It's done with GIS mapping system.
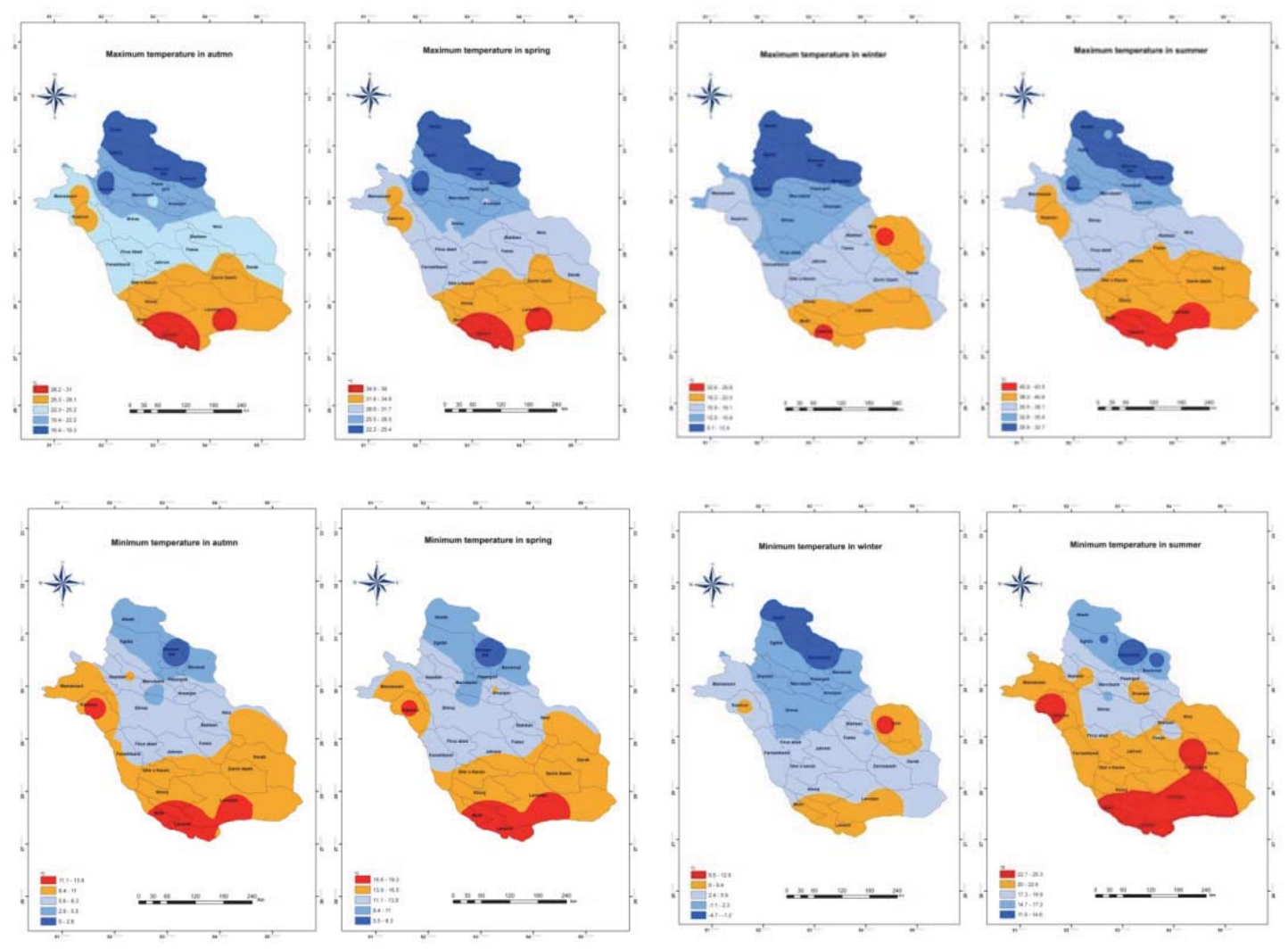

Fig 2. Heat and Cool Zones of Fars in Spring, Summer, Fall and Winter (2001-2010)

\section{Coefficient of Elasticity Times}

According to HDD and CDD functions, network load variation curve is shown as $L_{C D D}=f(C D D)$ and $L_{H D D}=g(H D D)$. Both functions are non-linear, and show an upward trend to reach a peak. These upward changes, particularly in cooling 
load function are very sharp. Elasticity coefficient demonstrates the sensitivity of the network load to temperature. The following graph represents the elasticity function for HDD and CDD in Fars power network during 2009.

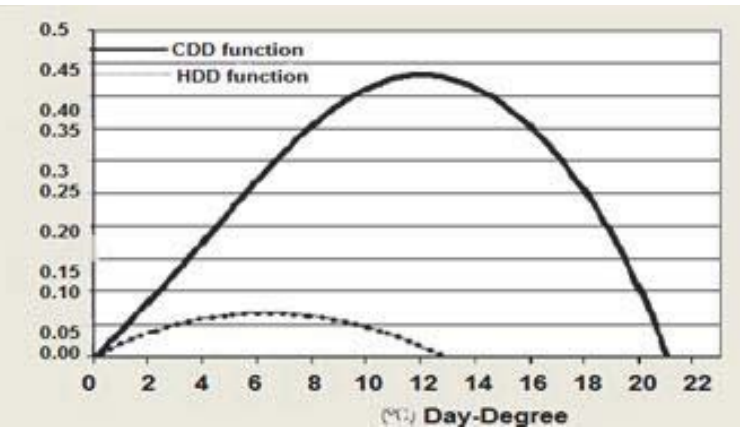

Fig 3. CDD and HDD Elasticity Function

Elasticity values for CDD function are much bigger than HDD. In other words, in the network load the sensitivity to the changes in hot period is higher than the cold period of the year. The highest elasticity occurs in 12 cooling degree days (CDD) and 7 heating degree days (HDD). The saturation point for CDD function is in 18 degree-days and $38^{\circ} \mathrm{C}$, and it is 7 degree-days and $9^{\circ} \mathrm{C}$ for HDD function.

\section{Conclusions}

In this study, the effects of climate change (specifically temperature) on the electrical energy consumed in Fars province were studied. Analyzing network load trend and temperature variations show a strong correlation between electric load and environmental conditions (particularly maximum air temperature). If seasonal temperature variation is compared with the correlation coefficients table, then it is confirmed that these two are directly related. Also, comparison of seasonal temperature changes with time and temperature correlation table confirms that the two are directly related. Finally, consumed load variation which is affected by air temperature is shown simulated by GIS mapping system. As it is observed, these two maps are closely related to each other. It means that the more increase in weather temperature, results in the more electric energy being consumed.
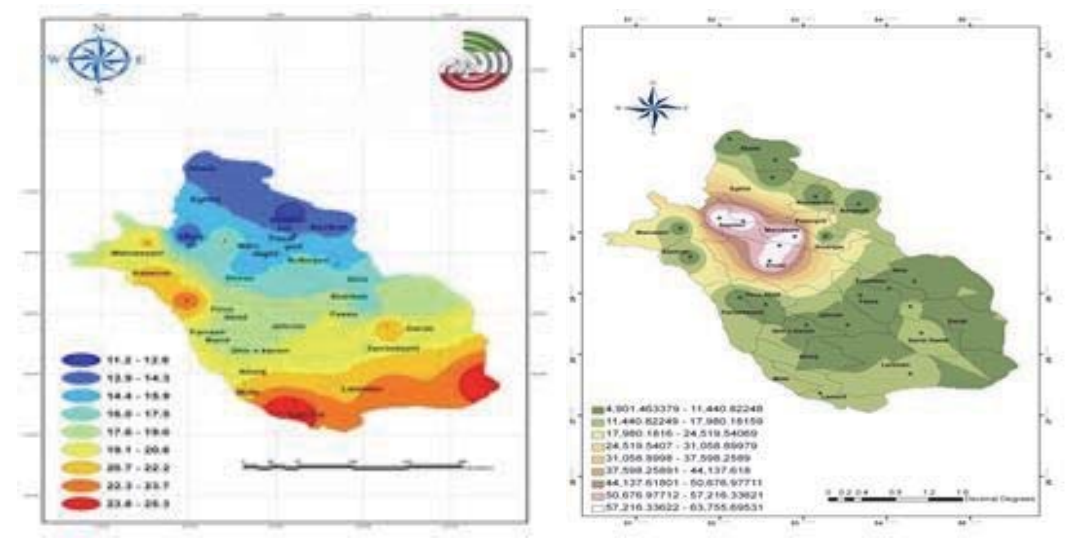

Fig 4. Simulating Thermal Map for Fars (2001-2010) FIG5. Electricity Consumption Map (2001-2010)

\section{References}

"Electricity Consumption In the Eastern Province of Saudi Arabia" Journal of Forecasting ‘Vol.15 ,Pp: 97-106.

Badr. E.A , Nasr.G.E, 2001 "On the Relationship Between Electrical Energy Consumption And Climate Factors in Lebanon: CoIntegration And Error-Correction Models" Int. J. Energy Res, Pp:1033-1042.

Bosello, F. , De Cian. E. , Rosen R. , 2007 "Climate Change ,Energy Demand and Market Power in a General Equilibrium Model of the 
World Economy " Dse Working Papers, No.09.

M. Christenson, H. Manz, D. Gyalistras, 2006 "Climate Warming Impact on Degree-Days and Building Energy Demand in Switzerland", Energy Conversion and Management $47 \mathrm{Pp}$ : 671-686.

Engle. R, Mustafa. C., J. Rice, 1992 "Modeling Peak Electricity Demand" J. Forecasting. 11, Pp:241-251.

Giannakopoulos. C., Psiloglou, E., 2006 "Trends in Energy Load Demand For Athens, Greece: Weather and Non-weather Related Factors" Climate Research, No. 31, Pp: 97-108.

Le Comte. D, Warren. H, 1981 "Modeling the Impact of Summer Temperatures on National Electricity Consumption " Journal of Applied Meteorology , Pp:1415-1419.

Psiloglou. E , Giannakopoulos. C, Magithia. S, 2007 "Comparison of Energy Load Demand and Thermal Comfort Levels in Athens, Greece and London, Uk" Aivc Conference on Building Low Energy Cooling. September, Pp:806-810.

Sailor. D, Munoz. J, 1997 "Sensitivity of Electricity and Natural Gas Consumption to Climate in the USA" Energy. 22, Pp: 987-998.

Valor. E, Meneu. V, Caselles. V, 2001 "Daily Air Temperature and Electricity Load in Spain" Journal of Applied Meteorology, Pp: 14131421. 
ISSN 2039-2117 (online) ISSN 2039-9340 (print)
Mediterranean Journal of Social Sciences MCSER Publishing, Rome-Italy
Vol 6 No 3 S2 May 2015 